\title{
Erratum to: Use of Conivaptan (Vaprisol) for Hyponatremic Neuro-ICU Patients
}

\author{
Andrew M. Naidech - James Paparello - Storm M. Liebling • \\ Sarice L. Bassin · Kimberly Levasseur • Mark J. Alberts • \\ Richard A. Bernstein · Kenji Muro
}

Published online: 6 May 2011

(C) Springer Science+Business Media, LLC 2011

\section{Erratum to: Neurocrit Care (2010) 13(1):57-61}

DOI 10.1007/s12028-010-9379-5

In article "Use of Conivaptan (Vaprisol) for Hyponatremic Neuro-ICU Patients", Storm Liebling's name was misspelled. The correct authorship is given here.

The online version of the original article can be found under doi:10.1007/s12028-010-9379-5.

A. M. Naidech $(\bowtie) \cdot$ S. M. Liebling · S. L. Bassin •

M. J. Alberts · R. A. Bernstein

Department of Neurology, Northwestern University,

710 N Lake Shore Drive, 11th floor, Chicago, IL 60611, USA

e-mail: a-naidech@northwestern.edu

J. Paparello

Department of Internal Medicine, Northwestern University,

710 N Lake Shore Drive, 11th floor, Chicago, IL 60611, USA

K. Levasseur

Northwestern Memorial Hospital, 251 E Huron, Chicago,

IL 60611, USA

K. Muro

Department of Neurological Surgery, Northwestern University,

710 N Lake Shore Drive, 11th floor, Chicago, IL 60611, USA 